\title{
Perancangan Sistem Informasi Akuntansi Pendapatan dan Piutang Mahasiswa Baru Berbasis Web Pada STMIK Rosma
}

\author{
Yeny Rostiani $^{1}$, Rahmat Gunawan ${ }^{2}$, Shantyasari ${ }^{3}$ \\ ${ }^{1,3}$ Komputerisasi Akuntansi, STMIK Rosma, Karawang \\ ${ }^{2}$ Manajemen Informatika, STMIK Rosma, Karawang \\ E-mail: yeny@rosma.ac.id
}

\begin{abstract}
Receivables are one of the elements in the balance sheet, and arise as a result of the sale of goods and services on credit or in installments. Currently, credit sales do not only exist in trading companies, in the world of education, payments in installments or stages are also applied, this is done to provide relief to students in terms of paying tuition fees, but if students do not pay on time or are in arrears it will cause receivables. Receivables are one of the company's most important assets, therefore they must be managed properly, accuracy in calculating and inputting is needed to avoid reporting errors. At STMIK Rosma, receivable data management still uses Microsoft Excel which is not equipped with a database that is prone to data loss or damage. Based on this description, the purpose of this study is to design an accounting information system for income and accounts receivable. The research method used is the System Development Life Cycle (SDLC) waterfall model. The result of this research is a web-based accounting information system for new students' income and receivables which is expected to help and speed up the process of inputting, searching and reporting.
\end{abstract}

Keywords: Accounting Information System, Accounts Receivable, Revenue, Web

\begin{abstract}
Abstrak
Piutang adalah salah satu unsur dalam neraca, dan timbul akibat adanya penjualan barang dan jasa secara kredit atau mencicil. Saat ini penjualan kredit tidak hanya ada dalam perusahaan dagang, dalam dunia pendidikan pun diberlakukan pembayaran secara cicilan atau tahapan hal ini dilakukan untuk memberikan keringan kepada mahasiswa dalam hal pembayaran biaya kuliah, akan tetapi apabila mahasiswa tidak membayar tepat waktu atau menunggak akan menimbulkan piutang. Piutang merupakan salah satu harta perusahaan yang sangat penting, oleh karena itu harus dikelola dengan baik ketelitian dalam menghitung maupun menginput sangat diperlukan untuk menghindari kesalahan pelaporan. Pada STMIK Rosma pengelolaan data piutang masih menggunakan Microsoft Excel yang tidak dilengkapi dengan database yang rentan datanya hilang atau rusak. Berdasarkan uraian tersebut, maka tujuan penelitian ini adalah merancang sebuah sistem informasi akuntansi pendapatan dan piutang. Metode penelitian yang digunakan yaitu System Development Life Cycle (SDLC) model air terjun (waterfall). Hasil dari penelitian ini adalah sistem informasi akuntansi pendapatan dan piutang mahasiswa baru berbasis web yang diharapkan dapat membantu serta mempercepat proses penginputan, pencarian maupun pelaporan.
\end{abstract}

Kata Kunci: Sistem Informasi Akuntansi, Piutang, Pendapatan, Web

\section{Article History :}

Received 25, Oktober, 2021

Revised 02, November, 2021

Accepted 17, November, 2021

\section{Corresponding Author:}

Nama Penulis, Yeny Rostiani

Departemen, Komputerisasi Akuntansi

Instansi, STMIK Rosma

Alamat. Jl. Kertabumi No. 62 Karawang

Email Penulis. yeny@rosma.ac.id 


\section{Pendahuluan}

Berkembangnya Ilmu Pengetahuan dan Teknologi (IPTEK) di era globalisasi saat ini, mendorong banyaknya alternative pemecahan masalah dibidang teknologi sistem informasi, dan menuntut setiap generasi muda harus mampu menyesuaiakan dan mengembangkan diri terhadap lingkungan yang akan dihadapinya dengan cara membekali diri dengan Pendidikan dan keterampilan. Pendidikan yang diperoleh saat di bangku perkuliahan baik teori maupun praktek diharapkan dapat membekali generasi muda untuk bersaing di dunia kerja.

Saat ini kesempatan untuk mendapatkan Pendidikan dapat dilakukan di berbagai perguruan tinggi baik negeri maupun swasta, bahkan di era pandemic seperti sekarang ini pembelajaran dilakukan secara daring sehingga memudahkan mahasiswa untuk mengakses pembelajaran dari berbagai tempat, dan situasi tanpa terkendala waktu.

Sekolah Tinggi Manajemen Informatika dan Komputer (STMIK) Rosma adalah salah satu perguruan tinggi yang ada di Kabupaten Karawang, berbagai program yang dilakasanakan oleh STMIK Rosma dalam mendapatkan calon mahasiswa baru salah satunya adalah program biaya kuliah murah, pemberian beasiswa bagi calon mahasiswa yang memiliki ranking 1 sampai 10 selama belajar di sekolah menengah, dan kebijakan lain yang diberikan kepada calon mahasiswa baru adalah adanya pembayaran secara cicilan atau tahapan sebanyak 9 tahap, hal ini dilakukan agar calon mahasiswa tidak merasa keberatan dengan biaya kuliah di STMIK Rosma.

Pencatatan pendapatan yang diperoleh dari mahasiswa baru saat ini diolah dan disimpan dalam Microsoft Excel yang mana setiap terjadi transaksi pembayaran biaya kuliah dari mahasiswa baru bagian keuangan menginput kedalam excel, dan apabila terdapat mahasiswa yang tidak tepat waktu melakukan pembayaran sesuai tahapan per bulannya maka akan dimasukan kedalam katagori piutang, ketelitian dalam menghitung maupun menginput sangat diperlukan untuk menghindari kesalahan pelaporan, dikarenakan penggunaan Microsoft Excel tidak dilengkapi dengan database yang rentan datanya hilang atau rusak.

Pada kesempatan penelitian ini penulis melakukan kegiatan observasi awal di bagian keuangan STMIK Rosma tentang pencatatan pendapatan dan besaran piutang mahasiswa baru, berdasarkan beberapa katagori yang ada saat ini.

Berdasarkan penjelasan di atas maka penulis merancang suatu sistem pencatatan menggunakan web untuk menampung semua data-data yang ada ke dalam database agar tidak terjadi kehilangan data ataupun data error.

\section{Tinjauan Pustaka \\ 2.1. Pendapatan}

Pendapatan biasanya berasal dari penjualan atau penyerahan jasa kepada pihak lain dalam periode akuntansi tertentu [1], selain itu pendapatan dapat timbul dari penjualan, proses penyimpanan (earning process). Dalam perusahaan dagang, pendapatan timbul dari penjualan barang. Pada perusahaan manufaktur, pendapatan diperoleh dari penjualan produk selesai, sedangkan pada perusahaan jasa, pendapatan diperoleh dari penyerahan jasa kepada pihak lain. Adapun jenis-jenis pendapatan dari satu kegiatan perusahaan adalah sebagai berikut :

a. Pendapatan Operasional

Menurut Dyckman, Dukes dan Davis (2002: 239) pada dasarnya pendapatan operasional timbul dari berbagai cara yaitu :

1) Pendapatan yang diperoleh dari kegiatan usaha yang dilaksanakan sendiri oleh perusahaan tersebut tanpa 
penyerahan jasa yang telah selesai produksi.

2) Pendapatan yang diperoleh dari kegiatan usaha dengan adanya hubungan yang telah disetujui,alnya penjualan konsinyasi.

3) Pendapatan dari kegiatan usaha yang dilaksanakan melalui kerja sama dengan para investor.

b. Pendapatan Non-Operasional (Pendapatan Lain-lain)

Pendapatam yang diperoleh dari sumber lain diluar kegiatan utama perusahaan digolongkan sebagai pendapatan non operasional yang sering juga disebut sebagai pendapatan lain-lain. Pendapatan ini diterima perusahaan tidak kontiniu namun menunjang pendapatan operasional perusahaan. Dari timbulnya pendapatan tersebut, dapat disimpulkan bahwa sumber pendapatan meliputi semua hasil yang diperoleh dari bisnis dan investasi. Kaitannya dengan operasi perusahaan, pada umumnya sumber dan jenis pendapatandapat dikelompokan sebagai berikut : Pendapatan dari Operasi Normal Perusahaan dan pendapatan dari Luar Operasi Perusahaan.

\subsection{Piutang}

Definisi piutang menurut Benny Alexandri (2009:117) adalah: Piutang merupakan sejumlah uang hutang dari konsumen pada perusahaan yang membeli barang dan jasa secara kredit kepada perusahaan [2].

Menurut Kieso dan Weygandt (2007:347) [3] Piutang dibagi menjadi dua bagian berdasarkan asal terjadinya, yaitu piutang dagang dan piutang non dagang. Piutang Dagang adalah piutang yang timbul dari penjualan secara kredit barang dagangan, barang hasil produksi, atau jasa yang dihasilkan, sedangkan Piutang Non Dagang adalah piutang yang timbul dari transaksi yang tidak secara langsung berhubungan dengan penjualan kredit misalkan piutang kepada karyawan dan pendapatan Bungan atau piutang kepada pemegang saham untuk mengendalian.

\subsection{Sistem Informasi Akuntansi}

Sistem informasi akuntansi adalah sebuah sistem yang memproses data dan transaksi guna menghasilkan informasi yang bermanfaat untuk merencanakan, mengendalikan dan mengoperasikan bisnis [4]. Sedangkan menurut Azhar Susanto adalah kumpulan (integrasi) dari sub-sub sistem/komponen baik fisik maupun non fisik yang saling berhubungan dan bekerja sama satu sama lain secara harmonis untuk mengolah data transaksi yang berkaitan dengan masalah keuangan menjadi informasi keuangan [5].

\subsection{Web}

Web atau Website adalah sejumlah halaman web yang memiliki cerita atau informasi yang saling berhubungan dan disertai gambar- gambar dan video [6].

Menurut Abdul Kadir (2005:2) World Wide Web (WWW) atau yang biasa di sebut Web merupakan salah satu sumber daya internet yang berkembang pesat. Saat ini, informasi Web didistribusikan melalui pendekatan hyperlink, yang memungkinkan suatu teks, gambar, ataupun objek yang lain menjadi acuan untuk membuka halamanhalaman Web yang lain. Berdasarkan pendapat para ahli di atas dapat disimpulkan bahwa definisi web adalah aplikasi sistem informasi yang berupa teks, gambar, suara dan multimedia yang berjalan pada internet atau intranet [7].

\section{Metode Penelitian}

Metode penelitian yang digunakan dalam penelitian ini adalah metode System Development Life Cycle (SDLC) merupakan sebuah metode yang digunakan untuk membuat sistem dengan menggunakan berbagai macam model dan model yang penulis gunakan pada penelitian ini adalah 
model pengembangan Waterfall (Air Terjun).

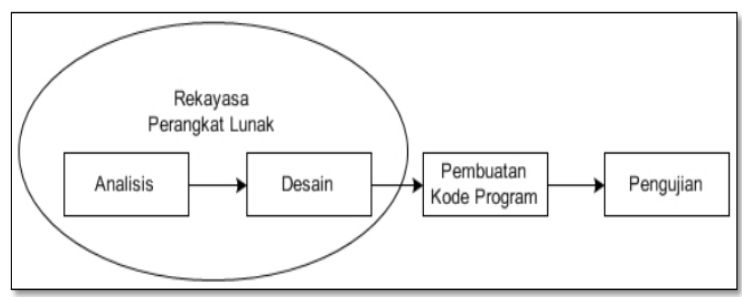

Gambar 1. Tahapan Waterfall

Menurut Rosa dan Shalahudddin (2015:29)[8] Metode Waterfall ini terdiri dari beberapa tahapan dalam sistematika pelaksanaan modelnya. Tahapan waterfall yang dimaksud, yaitu:

a. Analisis kebutuhan perangkat lunak

Sebelum sistem buat, diperlukan suatu analis sebagai dasar untuk mengetahui kebutuhan sistem ke depannya. Analisis kebutuhan sistem terdiri dari analisis kebutuhan fungsional yang bertujuan untuk mengetahui kebutuhan fungsi sistem dan analisis kebutuhan non fungsional untuk mengetahui perangkat keras dan perangkat lunak yang dibutuhkan serta kriteria pengguna sistem.

b. Desain

Desain berfungsi sebagai dasar perancangan yang mengubah data-data yang didapat dari analisis menjadi sebuah rancangan yang terdiri dari desain struktur data, struktur navigasi, dan rancangan antar muka.

c. Pembuatan kode program

Tahapan ini merupakan lanjutan dari tahapan desain, yaitu mentranslasi desain menjadi sebuah program. Tahap ini menghasilkan suatu program yang sesuai dengan desain.

d. Pengujian

Program yang telah dibuat wajib diuji terlebih dahulu untuk memastikan bahwa program layak digunakan dari segi logic maupun fungsional. Pengujian ini dilakukan untuk meminimalisir kesalahan (error) dan memastikan keluaran yang dihasilkan sesuai dengan yang diinginkan.

e. Pendukung (support) atau pemeliharaan (maintenance)

Program yang telah diuji dapat mengalami perubahan ketika sudah dikirimkan ke pengguna. Perubahan dapat terjadi karena terjadi kesalahan yang tidak terdeteksi saat pengujian program harus beradaptasi dengan lingkungan baru (hardware baru). Tahap pendukung atau pemeliharaan bertujuan untuk menjaga stabilitas program yang telah dibuat tanpa harus membuat program yang baru.

\section{Hasil dan Pembahasan}

\subsection{Identifikasi Sistem Berjalan}

Pada saat ini STMIK Rosma masih menggunakan Microsoft excel untuk pencatatan Pendapatan dan piutang, berikut ini adalah prosedur Pencatatan Pendapatan dan Piutang yang ada di STMIK Rosma karawang

a. Mahasiswa baru yang akan melakukan pembayaran menunjukan surat pembayaran kepada kasir. yang sebelumnya diberikan oleh marketing.

b. Kasir menerima sejumlah uang yang diberikan mahasiswa baru tersebut sesuai dengan jumlah yang tertera pada surat.

c. Jika uang sudah sesuai maka kasir akan dicatat manual oleh kasir pada Microsoft excel.

d. Kasir mencetak kuitansi sesuai dengan jumlah yang diterima.

e. Kuitansi diberikan kepada mahasiswa baru sebagai bukti bahwa mahasiswa tersebut sudah melakukan pembayaran. 


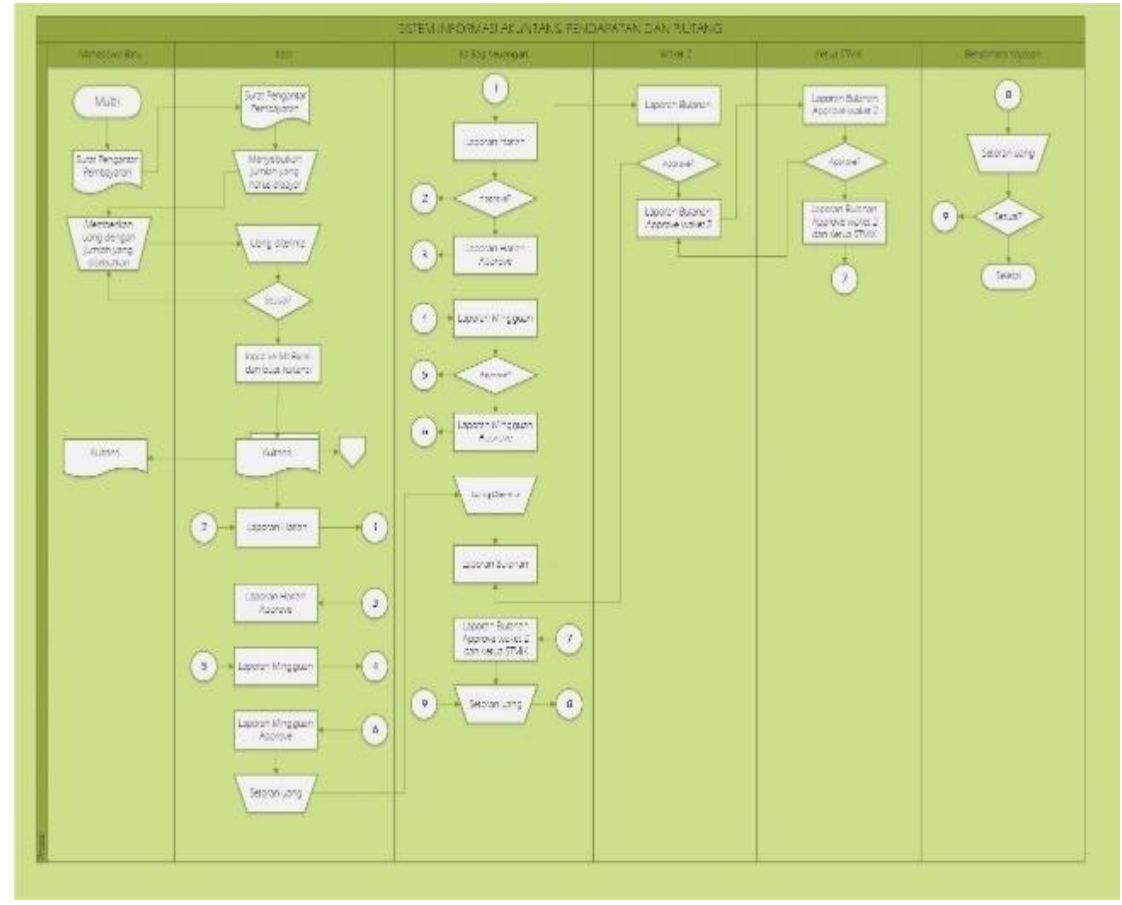

Gambar 2. Flowchat Sistem Berjalan

\subsection{Flowchart Sistem Usulan}

Berikut adalah flowchart sistem yang diusulkan oleh penulis setelah meneliti dari permasalahan yang ada pada sistem
Pencatatan Pendapatan dan Piutang pada STMIK Rosma :

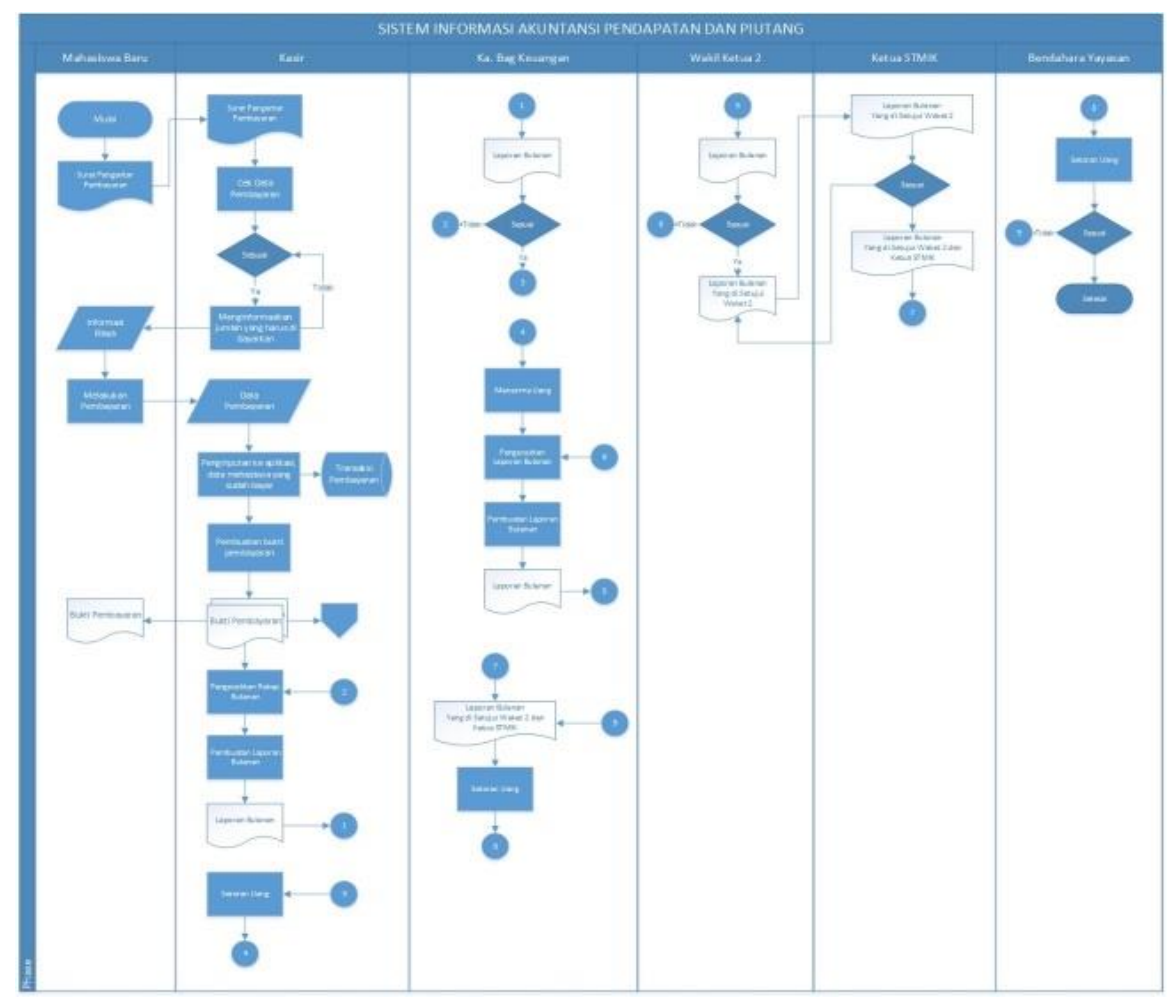

Gambar 3. Flowchart Sistem Usulan

Jurnal Interkom: Jurnal Publikasi Ilmiah Bidang Teknologi Informasi dan Komunikasi

Volume 16 Nomor 03 Bulan Oktober - Tahun 2021 


\subsection{Diagram Konteks}

Diagram konteks merupakan diagram yang menggambarkan kondisi system yang baik input maupun output pada system serta menyatakan terminator yang terlibat dalam penggunaan system. Diagram ini akan memberikan gambaran tentang keseluruhan sistem [9]. Berikut diagram konteks yang digunakan dalam perancangan sistem ini.

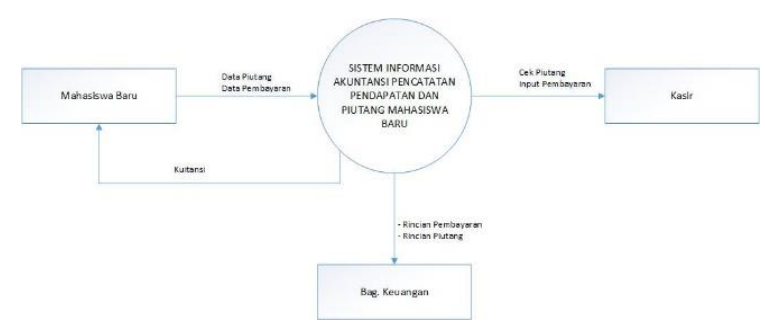

Gambar 4. Diagram Konteks

\subsection{Data Flow Diagram}

Data Flow Diagram (DFD) atau diagram arus data adalah jenis dari sebuah pemodelan proses yang digunakan untuk menggambarkan aliran dari data pada suatu sistem dan proses atau kerja yang dikerjakan pada sistem [10].

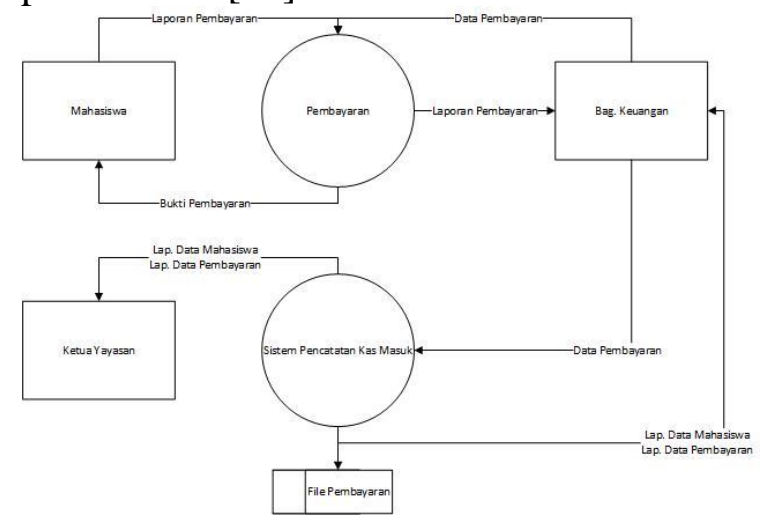

Gambar 5. Data Flow Diagram

\subsection{Implementasi Sistem}

Perancangan Sistem Informasi Akuntansi Pendapatan dan Piutang Mahasiswa Baru Berbasis Web pada STMIK Rosma ini memiliki beberapa Form yang harus diisi, berikut ini penulis tampilkan gambar tampilan sebagai berikut:

\section{a. Form Login}

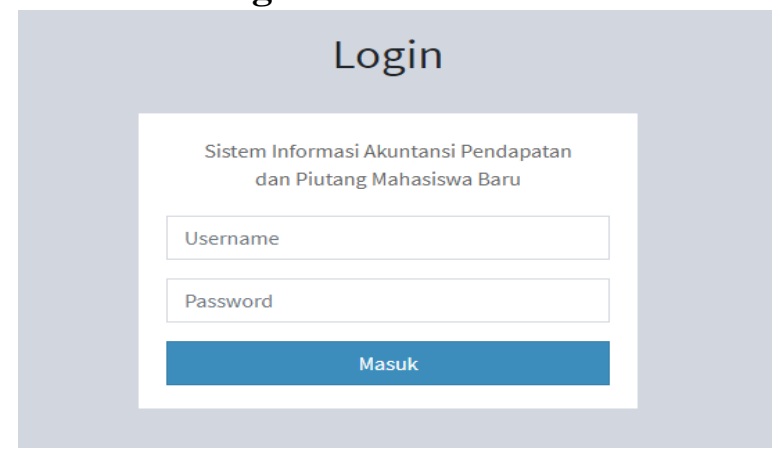

Gambar 6. Form Login

Form diatas adalah Form Login, User atau Admin harus memasukan Username dan password untuk dapat mengakses aplikasi ini.

\section{b. Form Tampilan Awal/ Beranda}

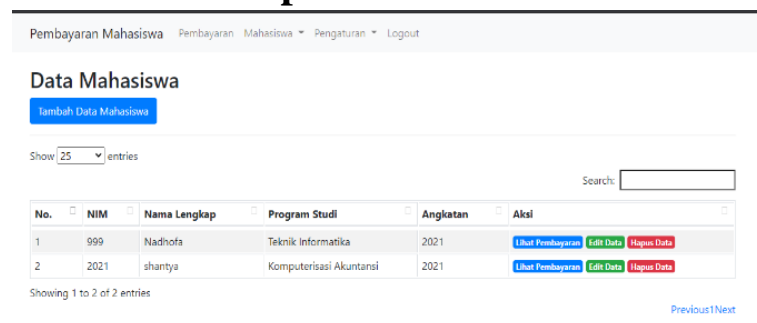

Gambar 7. Form Tampilan Awal

Form ini adalah form awal yang ditampilkan saat user atau admin benar dalam memasukan username dan password

\section{c. Form Lihat Pembayaran}

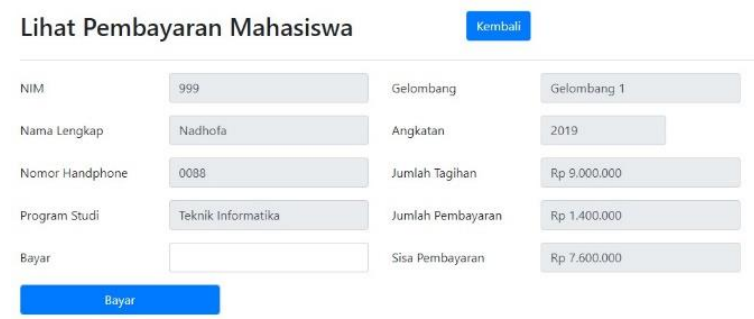

Gambar 8a. Form Lihat Pembayaran

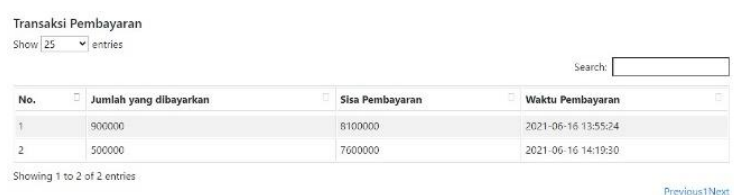

Gambar 8b. Form Lihat Pembayaran 
Form ini adalah form yang akan menampilkan berapa jumlah tagihan, jumlah pembayaran/pendapatan dan sisa pembayaran/piutang.

\section{d. Form Tambah Data Mahasiswa}

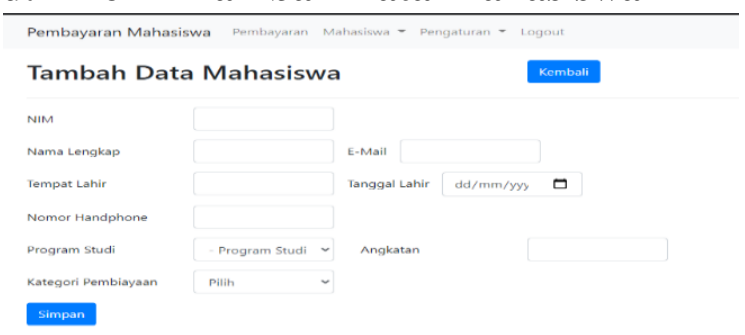

Gambar 9. Form Tambah Data Mahasiswa

Form tambah data mahasiswa ini dikhususkan untuk admin menambahkan data mahasiswa baru agar pencatatan pendapatan atau piutang dapat terrecord secara akurat.

\section{e. Form Data Pembiayaan}

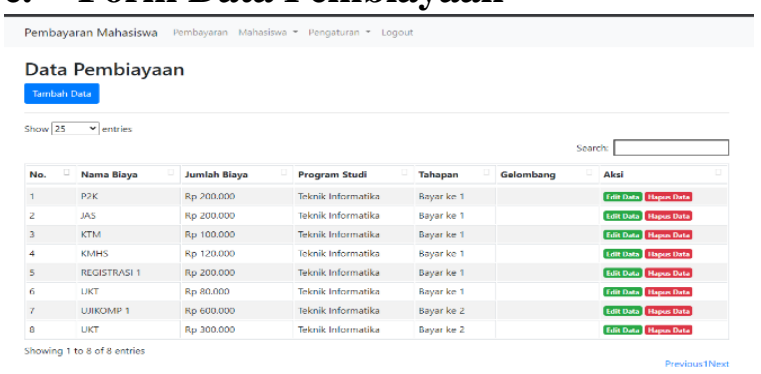

Gambar 10. Form Data Pembiayaan

Pada Form Data Pembiayaan ini form untuk melihat data pembiayaan untuk mahasiswa baru.

\section{f. Form Tambah Data Pembiayaan}

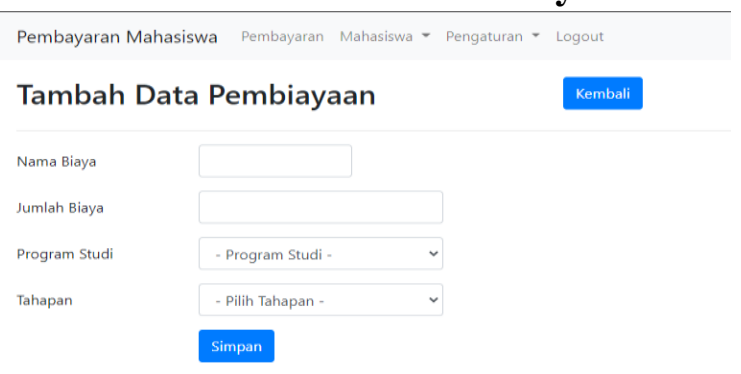

Gambar 11. Form Tambah Data Pembiayaan
Form ini adalah form data master untuk menyeting seluruh pembiayaan yang ada.

\section{Kesimpulan}

Berdasarkan hasil analisis data dan pembahasan pada bab sebelumnya, maka dapat diambil kesimpulan sebagai berikut:

a. Kegunaan (Usability), kesimpulan yang dapat diambil terdapat indikator yang sesuai dengan variabel kegunaan (Usability) yaitu "Kemudahan untuk dioperasikan" Jurnal.id adalah aplikasi berbasis website yang sangat mudah digunakan oleh pengguna, tampilan pada jurnal.id memberikan kemudahan untuk dioperasikan pada setiap pengguna di PT.Wahana Sakti dengan website yang jelas dan dapat dimengerti.

b. Kualitas Informasi (Information Quality), kesimpulan yang dapat diambil terdapat indikator yang sesuai dengan variabel kualitas informasi (information quality) yaitu "menyediakan informasi yang up to date" Jurnal.id memberikan informasi yang up to date melalui via chat online yang terdapat dalam aplikasi Jurnal.id berbasis web. Namun untuk indikator "menyediakan informasi yang detail dan tepat" masih terdapat kekurangan pada Jurnal.id yaitu pengguna tidak bisa meminta tampilan yang ada didalam aplikasi Jurnal.id sesuai keinginan.

c. Kualitas Layanan Interaksi (Service Interaction Quality), kesimpulan yang dapat diambil terdapat dua indikator yang sesuai dengan variabel kualitas layanan interaksi (service interaction quality) yaitu "kualitas layanan yang mempunyai reputasi yang baik" dan "adanya rasa aman dalam menyampaikan data pribadi”. Dapat diketahui bahwa kualitas layanan pada Jurnal.id mempunyai reputasi yang baik, respon dari setiap customer service jurnal sangat cepat dan tanggap,

Jurnal Interkom: Jurnal Publikasi Ilmiah Bidang Teknologi Informasi dan Komunikasi

Volume 16 Nomor 03 Bulan Oktober - Tahun 2021 
serta kualitas layanan Jurnal.id bisa memberikan rasa aman untuk pengguna menyampaikan data pribadi.

\section{Daftar Pustaka}

[1] V. A. Lumingkewas, "Pengakuan Pendapatan dan Beban Atas Laporan Keuangan Pada PT. Bank Sulut," J. Chem. Inf. Model., vol. 53, no. 9, pp. 1689-1699, 2013.

[2] Wardokhi and N. Khikmah, "Analisis Penerapan Piutang Berdasarkan PSAK No. 07 Pada PT. Inti Bangun Buana Lestari Dengan PT. Inti Bangun Cipta Karya," in PROSEDING SEMINAR NASIONAL AKUNTANSI, 2020, pp. 1-7.

[3] F. Octaviany and N. Anasari, "ANALISIS TINGKAT PERPUTARAN PIUTANG PADA PT . ANUGRAH TEXTILE DI JAKARTA," vol. 5, pp. 1-8, 2020.

[4] T. Rahmasari, "Perancangan Sistem Informasi Akuntansi Persediaan Barang Dagang Pada Toserba Selamat Menggunakan Php Dan Mysql,"”is Best [Accounting Inf. Syst. Inf. Technol. Bus. Enterp., vol. 4, no. 1, pp. 411-425, 2019, doi: 10.34010/aisthebest.v4i1.1830.

[5] A. R. Asari, "Perancangan Sistem Informasi Akuntansi Pembelian Pada PT Khomsah Khalifah Dengan
Menggunakan Software PHP dan MySQL," @ is Best Account. Inf. Syst. Inf. Technol. Bus. Enterp., vol. 3, no. 1, pp. 249-261, 2018, doi: 10.34010/aisthebest.v3i1.1816.

[6] A. Sahdilla, "PERANCANGAN SISTEMINFORMASI PENJUALAN OBAT PADA APOTEK DIAN BERBASIS WEB," INFORMATIKA, vol. 9, no. 2, pp. 1-8, 2020.

[7] S. Sofyan, D. Agustine, and E. Oktora, "Sistem Aplikasi Raport Berbasis Web pada SMA Muhammadiyah 2 Cipondoh Kota Tangerang," J. Ilm. Mhs. Fak. Tek., vol. 1, no. 2, pp. 89-95, 2021.

[8] Swastika, "Bab II Landasan Teori," J. Chem. Inf. Model., vol. 53, no. 9, pp. 1689-1699, 2019.

[9] L. Setiyani and E. Tjandra, "PERANCANGAN DAN IMPLEMENTASI DATA WAREHOUSE UNTUK PERPUSTAKAAN KAMPUS (STUDI KASUS : STMIK ROSMA KARAWANG)," IJIS-Indonesia $J$. Inf. Syst., vol. 5, no. 2, pp. 112-123, 2020.

[10] Y. Rumdiana, "Pemodelan Proses Bisnis Pada Departemen Procurement Di Pt . Adhi Luhung Wicaksana," Ensains, vol. 3, no. 2, pp. 112-121, 2020. 